\title{
IRREDUCIBLE JUXTA-EPIPHYSIAL FRACTURE OF A FINGER
}

\author{
W. VON RAFFLER, INVERNESS, SCOTLAND
}

From Raigmore Hospital, Inverness

Juxta-epiphysial fractures of the fingers are frequent injuries and seldom present difficulty in reduction of the displacement. This is the report of a case of a fracture of the base of the proximal phalanx of the little finger near the epiphysis which could not be reduced by manipulation.

Case report-A boy aged seven years caught his right little finger between the spokes of a wheel and sustained a hyperextension injury. Radiographs showed what appeared to be a simple fracture close to the epiphysis of the proximal phalanx with a typical metaphysial triangle and dorsal tilting of the phalanx. It was manipulated under general anaesthesia and a plaster applied. Review showed that the reduction was unsatisfactory. Remanipulation of the fracture forty-eight hours after the original injury proved more difficult than was expected.

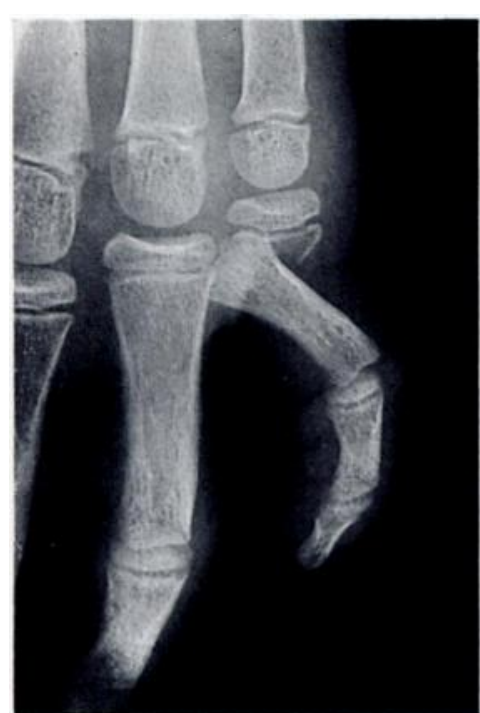

FIG. 1

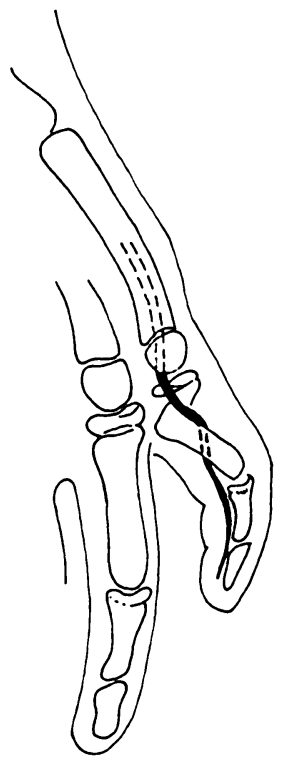

Fig. 2

Figure 1-Radiograph before operation. Figure 2-Diagram showing the findings at operation.

The fragments appeared to be mobile but after two unsuccessful attempts to gain a satisfactory position, as shown by radiographic control, operative reduction through a dorso-ulnar incision was undertaken. It was obvious that manipulation could never have succeeded. The flexor tendons lay on the dorsum of the shaft of the proximal phalanx and were trapped. After retraction of the the flexor tendons it was quite easy to lift the shaft of the phalanx and the fragments of the fracture then fell into line, resulting in a stable reduction.

Comment-I have been unable to find any reference in the literature to juxta-epiphysial fracture of the phalanx which was irreducible by manipulation because the flexor tendons were trapped on the dorsum of the phalanx. No doubt the injury has occurred without being thought worthy of record.

\section{I would like to thank Mr B. Dewar for the illustration.}

